But there is another point to be here considered : the hypertrophied prostate prevents the free escape of the fragments. Many will undoubtedly pass, but still many will remain behind, and therefore it becomes necessary to wash the bladder well out by means of a catheter of a peculiar constructionnamely, one with a long eye on the concave. Many fragments will pass away by this. A repetition of the operation is required, and the same washing out of the bladder is requisite. In the casse alluded to, although every care and attention were used, there were many fragments which could not be got away by the ordinary means, and therefore the scoop-lithotrite was used to bring away such as would not pass by the natural efforts, or by the washing out of the bladder. Notwithstanding every precaution, there was a single fragment evidently remaining, which I could not reach by the ordinary means. I therefore used a scoop-lithotrite an inch longer than that in common use, and removed it readily by this, and the case was effectually cured.

If you are not exceedingly particular in getting away every fragment of stone in cases of enlarged prostate, you may jus as well have let the case alone from the beginning, as all the symptoms of stone will be aggravated by the injury the bladder has sustained by your instrumentation. A friend of my own, who underwent the operation of lithotrity on more than one occasion, eventually died unrelieved after immense suffering. Two fragments were found behind an enlarged prostate, these had formed the nuclei of calculous concretions, and gave rise to symptoms of the greatest severity, which gradually wore him out. He suffered so much whenever an instrument was passed into the bladder that at length he was determined to submit to it no longer, although he was urged to it by his surgeon repeatedly. Chloroform was not in fashion at that period; and I think it was one of the few cases of lithotrity in which the use of that potent anæsthetic wonld have been amply justified.

In the course of last summer, I had an old gentleman under my care with symptoms of stone, accompanied with hypertrophied prostate. He complained at first of a frequent desire to pass urine without pain; and I treated his case, for a long time, as one of simple hypertrophy of the prostate, by occasionally drawing off the urine. However, the irritablitity of his bladder still continued; and he told me that he now began to suffer pain, especially on riding in a carriage. My sus. picions were at once excited; and, by examining him in the recumbent position, after the plan I have mentioned, I had no difficulty in detecting a calculus. I advised him to lay up for as short time, until his bladder became more quiet, and I told him I would then endeavour to break down the stone in the bladder.

The case is interesting for a variety of reasong, and is the type of a class of cases of very common occurrence. I could not succeed by any means in remoring the irritability of the bladder; and during my attempts to do so, he had a smart attack of gout, and his urine became nearly as red as blood by the deposit of an enormous quantity of the purpurate of ammonia. After the subsidence of this attack, I determined to wait no longer, and therefore proceeed to lithotritize him.

There was not the least difficulty in seizing the stone and breaking it up. After the first operation the irritability of the bladder subsided to a very great extent, and this you will find very often the case; but the case is important for this reason -namely, the difficulty in the removal of the fragments. Although this patient passed an immense number of small frag. ments per urethram unaided, yet to get rid of the entire stone or stones (for I think there were more than one) it was absolutely necessary to introduce the lithotrite or the scoop lithotrite at least thirty times. The enlarged prostate would not allow any fragments of large size to be expelled, and hence the necessity for repeating the operation so frequently. This was done with great care, and every introduction of the lithotrite was preceded by the drawing off of the urine, and the injection of the bladder with warm water. On some occasions it was necessary, after the blades of the lithotrite had been separated and well depressed into the bas-fond of the bladder, to lift up the pelvis to a great height before a fragment would fall in; then it was necessary to give a gentle shake of the lithotrite to seize the fragments; but by dint of great perseverance they were wholly got rid of, and the old gentleman was effectually cured. He was a man of good constitution, and suffered comparatively little constitutional disturbance during the rather rough treatment he was thus necessarily subjected to.

Chorens.-The cholera is said to have appeared in the Austrian army in Galicia.
REPORT OF A CASE OF

WOUND OF THE PALMAR ARCH, FOLLOWED BY SERIOUS HAMORRHAGE,

BOR THE CUBB OR WHICH

THE ULNAR, RADIAL, BRACHIAL, AND AXILIARY ARTERIES WERE SUCCESSFULLY TIED.

BY F. CARPENTER SKEY, EsQ, F.R.S.

Perhaps in no one circumstance does the practice of the modern surgeon differ more widely from that of our predecessors - the surgeons of half a century ago-than in the treatment of wounds of the larger arterial trunks of the body. At the period to which I allude, the wound of any considerable vessel, if unchecked by pressure, not uncommonly led to the final catastrophe of amputation of the limb. It is true that the doctrines and the practice of $\mathrm{Mr}$. Hunter were not unknown to his friends and followers, but it was not until Dr. Jones and $\mathrm{Mr}$. Hodgson in England, and Scarpa in Italy, had ascertained, by a series of conclusive experiments the most interesting and important, the full value of the machinery of the arterial system; and perhaps $i^{2}$ is not too much to assert that their experiments tend to the conclusion that under farourable cir. cumstances the entire current of blood which circulates throughout the arterial system may be diverted into new channels; and, if we except the great trunk itself, that not one ressel so developed shall justify either the name or the description given to it by the anatomist. Amongst the various conditions essential to a successful issue of all operations on large arteries is that of at least a moderate share of tonic health, a vigour of system that ensures certain changes in the blood whenever it becomes extravasated, and a vitalizing power which will per. fect the union of two surfaces brought into entire apposition with each other.

In the case the particulars of which I am about to relate, are presented two features of remarkable interest. The first involves the successful issue of an operation, or rather of a series of operations on the arterial trunks of a man whose constitution exhibited a deficiency of that tonic health and vigour of system to which I have referred, and the almost total absence of the vitalizing power which is indispensable to the union of two opposing surfaces of cellular tissue when brought into precise contact with each other. It is well known to medical authorities that there exists a class of persons of a debilitated and scorbutic habit, whose blond, however efficient it may have proved as a material of growth, however compatible its composition with a certain amount of physical strength, is yet destitute of that ingredient which ensures coagulation whenever the circulation is arrested within a vessel or escapes beyond it. This condition of the circulating finid, which is hereditary in families, is marked by a hæmorrhagic tendency. The slightest injury to the surface of the body is followed by the oozing of blood for hours; the act of cleaning the teeth occasions the same discharge of blood from the gums; the extraction of a tooth is followed by hremorrhage often of a formidable character, the results of which have not unfrequently proved fatal. This hromorrhagic condition is probably due to that of the blood, which fails in its property of coagulation. Cer. tainly such was the character of the subject of the following case:-

A man named James B-, aged twenty-eight, who presented himself at St. Bartholomew's Hospital on the 3rd of February last, having suffered from repeatedly recurring hæmorrhage, cansed by a wound in the palm of the hand, accidentally inflicted by himself on the previous 17 th of January in the attempt to cut a piece of leather with a blunt knife, the point of which slipped and penetrated the left hand, at the part where the ulnar artery enters the palm. The bleeding, as reported by himself, was most profuse, and was unchecked by any of the temporary expedients usually resorted to on board ship, where he was occupied as a workman.

He was admitted into the Hospital on the day of the accident; no bleeding vessel could be discovered, and a compress was applied. Hrmorrhage returned in the course of the night, and, a bleeding orifice being discovered, a ligature was placed round it. The man remained in the hospital during a few days, and, contrary to medical advice, persisted in returning home. On reaching his own dwelling, hæmorrhage to an alarming extent recurred. A surgeon in the vicinity attended, who checked it by means of pressure. The bleeding returned at short intervals on several occasions until February 3rd, 
when he was received into St. Bartholomew's Hospital. The latest severe attack of hæmorrhage occurred on March 30th, four days prior to his admission. The man appeared exceeding weak and anæmic, and his pulse was very small and frequent. From the ulnar side of the palm a wound of about an inch in length crossed somewhat obliquely the palmar arch. The palm was greatly swollen, and from the ragged unhealthy wound, and from various orifices, exuded a foetid, puriform fluid. The tumefaction extended through the hand to the dorsal aspect, which was also much swollen. The last phalanges of the index and middle fingers were gangrenous; the entire hand and arm were cedematous, and two lines of pretty actively inflamed absorbents extended to the elbow.

Such was the exact physical condition of this man at the outset of his treatment in St. Bartholomew's Hospital, the positive nature of whose injury, serious as it certainly was, was small and insignificant when compared with the career of suf. fering he had himself to undergo, and the labour and anxiety of mind he subsequently occasioned to others. In the following statement I propose to combine the facts of the case with the motives which dictated the practice adopted throughout.

On the arrival of the man at the hospital, I tied his radial and ulnar arteries at about an inch above his wrist-joint. The cedematous condition of the arm rendered these two small operations somewhat more troublesome than they are usually found. During the violent struggles of the man while inhaling chloroform a large abseess in the palm burst, and discharged a large quantity of most foetid pus. Eminent surgical authority would have fully justified a ligature on the brachial artery. preferred the radial and ulnar, which I have tied for similar injuries some twenty-five times without the recurrence of hæmorrhage in any one case, and this case cannot be deemed an exception. A linseed poultice was applied to the hand, and the man was ordered one drachm of tincture of cinchona three times a day, with six ounces of wine. In the course of the following week the patient's health improved, the wound became cleaner and healthier, and an abscess at the back of the hand burst, and discharged tolerably healthy pus.

Thus he progressed till the 10th of February, the 8th day after the operation, when blood in small quantity appeared in the ulnar wound. I requested that a tourniquet should be loosely applied. around the upper arm, and that the man should be watched.

On the 12th (the tenth day), the ulnar ligature separated, and hæmorrhage from the proximal end of the vessel followed. The tourniquet was immediately tightened by the sister of the ward. This circumstance having occurred at midday, I had the advantage of the opinions of my colleagues as to the course to be pursued. It was suggested that an attempt should be made to tie the ulnar artery in the palm. It has been a rule with me throughout life never to attempt to tie the ulnar artery beyond the carpal joint, even in a healthy hand. That proposition, therefore, was declined, as both inefficacious, and, in a surgical sense, impossible. It was then suggested that the ulnar artery should be tied at some distance above the former ligature. This course, though scarcely meeting the emergencies of the case, appeared to predominate in the minds of my colleagues, and I yielded to a general opinion. When a surgeon calls for a consultation with his colleagues, he is almost compelled to act in unison with their opinion. Such was my feeling, and I yielded accordingly. The man was a second time brought into the operating-theatre, and I tied the ulnar artery at about four inches above the wrist.

$\mathrm{He}$ progressed favourably until the 16th (four days after the last operation), when hæmorrhage returned with violence from both the proximal end of the vessel, at the point at which it had been last tied, and from the distal end, at which it was first tied. There was also considerable oozing from the palm. The term " favourable progress" requires, however, explanation. Judging from his improved aspect, his falling pulse, his greater inclination for food, and the cessation of bleeding, his progress was undoubtedly satisfactory; but it was obvious, that as regards the wound, whether of the hand or forearm, that no advance had been made of a positive kind towards their reparation. Of granulations there were none. The surfaces looked glazy, and rather wanting in action than exhibiting any tendency to increase, whether by ulceration or slough. ing. It was also observed, that the blood which had collected about his bed-clothes, and on the floor, did not coagulate like ordinary healthy blood. This second attack of hæmorrhage subsequently to my first operation on the radial and ulnar arteries occurred between two and three in the morning of the 16th, within an hour after which I reached the hospital. The patient, sadly reduced from loss of blood, which had flowed for some minutes, while partially arrested only by himself, in his ineffectual attempt to tighten the tourniquet, now constantly applied, was again laid upon the operating-table, where I tied the brachial artery between the origins of the inferior profunda and the anastomotic branch. In consequence of the ressel being surrounded by a plexus of veins of large size formed by cross branches of communication between the venæ comites, two of which I was compelled to tie, I had some difficulty in clearing the artery to admit of the passage of the needle around it; and the difficulty of the operation was further increased by the odematous state of the arm, and by the imperfect substitute for natural light afforded by gas. The wound was carefully closed by adhesive plaster. The entire operation occupied from twenty to twenty-five minutes. He was ordered disulphate of quinine, three grains; dilute sulphuric acid, twenty minims: every four hours. Animal food three times in the day, and six ounces of wine. This operation was followed by a temporary lull of nine days' duration, which gave earnest of a successful issue to the case, during which the man's appetite, pulse, and sleep, one and all, gave indication. of a gradual, though slow, restoration of his physical health, with this important drawback howerer-viz., that none of the wounds had made any advance in the direction of healing. These anticipations were not realized.

At eleven o'clock on the night of the 17th, the ulnar artery, at its distal end, burst out, profuse hæmorrhage followed, and at the same time blood oozed freely from the wound over the brachial artery. The tourniquet was again tightened, and the arm rolled, but the quantity of blood again lost told painfully on the condition and aspect of the man, who, however, revived under brandy and other stimulants. The quantity lost was estimated at about ten ounces. I reached the hospital at midnight, full of anxiety as to the future. The impression of his condition was such that I was not surprised to find the operatingtheatre lighted up, and the instruments of amputation all laid out ready for use. Four operations had been already performed without success. It was clear in the then, though somewhat improved condition of his health, that the contact during many days of the opposite surfaces of the arterial tubes did not lead to their permanent union, and it was not improbable that another coup would prove fatal. Could I under these circumstances risk another and yet more fornidable operation by placing a ligature round the axillary artery? His recovery from the recent hrmorrhage would be necessarily slow, and that hæmorrhage alone would militate against such rapid improvement in his healthas, under more favourablecircumstances, might possibly be obtained by judicious diet and medical treatment. On the other hand, the objection, to amputation appeared, if possible, yet more formidable. No management could prevent the loss, during its performance, of a considerable quantity of blood. The application of a tourniquet was impracticable, because the arm must have been removed either at the articulation or immediately below it, and when the then state of the lesser wounds was taken into consideration, what hope remained that so large a wound as that formed by the face of a stump should undergo a better fate? It is very true that a large vessel tied in a stump might be placed in a more advantageous position for obliteration than a vessel which is merely interrupted in its course by the application of a ligature around it. But even this was by no means conclusive. I was mainly influenced by the condition of the former wounds, not one of which had even advanced in its healing process.

Under these circumstances, and in the hope that I might yet succeed in my effort to alter, and to improve, the abnormal condition of the man's constitution by active means, some evidence of which had peered out during the last week, the poor fellow was for the fourth time conveyed into the operating. theatre, at half-past twelve at night, (i. e., on the 18th, when I tied the axillary artery between the long thoracic and infrascapular branches, by an incision of some two inches in length, carried along the lower margin of the pectoralis major muscle. As in the operation on the brachial, the difficulties were not slight. The manipulation on the left axilla by the right hand; the necessary dissection of the parts, nearly at arm's length, in consequence of the impossibility of approaching sufficiently closely to the patient, and which compelled me to perform a part of the dissection with the left hand; the proximaity of the axillary vein to the artery; the contiguity of the brachial plexus, and more especially of the vlnar and internal branch of the median nerves, tightly drawn down on the vessel by the neces. sary extension of the arm, and each of which was exposed; the depth of the wound in relation to its length; its inaccessibility to vertical light from the position of the body; --such were the obstacles to a rapid completion of the operation, which must 
have presented themselves to the notice of all. Half an hour had elapsed before it was completed. The edges of the wound were brought carefully into contact, and the man carried to his bed. He was ordered tincture of cinchona bark, three drachms, and gallic acid, ten grains, every four hours; ten ounces of wine, and animal food, as before, thrice daily; eggs, as many as he could eat. The arm was rolled firmly by means of a bandage, because, although I deemed it a measure not unlikely rather to increase the liability to general gangrene of the entire extremity, yet every other care and consideration now merged in the question of life.

On the following day, the man had rallied more than could reasonably have been expected from his condition on the previous night, and took his food and medicine without much difficulty.

Hæmorrhage again recurred from the situation of the brachial wound at nine P.M. on the 19th. The loss of blood was comparatively slight, and was checked by the application of lint and carefully-adjusted pressure. At this date, the extravasated blood presented the condition of partial coagulation.

On the 20th, bleeding from the brachial wound, which appeared in the form of general oozing, was checked by lint saturated with oil of turpentine.

On the 2lst, serious hæmorrhage recurred from the brachial artery, at one A.M.

I reached the hospital at three $A_{\text {. }}$ M., with a very reduced hope of saving the man's life. However, both I and my junior colleagues (the house-surgeon, Mr. Stanwell, and the dressers) were one and all firmly resolved that the poor fellow should not die from the want of care or watching. The arm was bared, and the brachial wound was accurately filled with scraped lint, a graduated compress was rolled firmly over the course of the vessel, a charcoal poultice was applied to the hand, and he was ordered twenty-five minims of tincture of opium, twelve ounces of sherry, and six ounces of brandy, daily.

From this date to March 1st, the man's condition again improved considerably. His pulse fell from 130 to 100 , he had gained a healthier aspect, and slept well, so long as he was watched. During the week, he had taken a large quantity of the most nutritious food, and he had digested it with the greatest benefit.

On the evening of March 1st, however, on the eleventh day from the last operation, at half-past nine, $a$ sudden burst of hæmorrhage occurred from the axillary trunk, that deluged

the bed with blood in a few seconds. Fortunately, past experience had rendered every person concerned on the alert. The nurse of the ward was sitting at the bed-side, and she partially arrested the bleeding by tightening the subclavian tourniquet. The sister of the ward, a most intelligent and most conscientious superintendent of a sick chamber, who lay down in her clothes, within a few feet of the man's bed, was also at his bed-side in the course of a few seconds, and within a period of three or four minutes Mr. Stanwell and one or two dressers were also in attendance. The bleeding, which had been by far the most formidable of any that had yet occurred, was again arrested by the firm pressure of the readjusted tourniquet. Again $I$ visited the hospital during the night, with the combined feeling of disappointment at the ill success of our past struggles for victory, and a firm resolntion to fight the battle to the last. The important question of amputation was again raised, and fully considered by myself and $\mathrm{Mr}$ Savory, of whose sound judgment I more than once availed myself in my numerous nightly visits.

The case at that time stood thus: I had already tied the last artery that could afford any hope of restraining the rerepeated attacks of hæmorrhage; that artery had burst. It is a venerable practice, sanctioned by time and by custom, that if secondary hæmorrhage of a formidable kind occur from the main artery of a limb, after the application of a ligature, that amputation of the limb is not only a warrantable proceeding, but presents the only alternative to the preservation of life. But did that principle apply to the case in question? certainly not. There were, in fact, three courses open to me: 1 . To put a ligature round the subclavian artery. 2. To amputate the arm at the shoulder-joint. 3. To resort to pressure; or, in other words, to temporize with the case.

With respect to the first course; I had tied the radial, the ulnar twice, the brachial, and finally the axillary, and every artery had burst. What reasonable hope could be entertained that I should be more successful in the case of the subclavian? All the strength the man had acquired by the administration of wine and the most nutritious food had been dissipated in a moment. The lost ground had again to be retraced by a weary and exhausted step. The physical impulse of the current within the subclavian would prove more fatal in proportion as the vessel was larger and the surface to be united more extensive- $\dot{a}$ fortior $i$ the prospect was less encouraging; and, again, should hæmorrhage occur, it would not only be more likely to prove immediately fatal, but, from its situation on the trunk, would not admit of so ready or convenient an application of pressure. I early relinquished this, as a course wortiny of adoption.

The second course involved the question of amputation. If performed at all, it now imperatively demanded the removal of the arm at the shoulder-joint. It was not improbable. looking to the present condition of the man, that the loss of blood inseparable from this operation under the best conditions might prove immediately fatal : and if it did not, what guarantee did I possess, that every single artery in the stump might not prove the source of secondary hæmorrhage. Besides, there remained another objection to the operation of removal that was conclusive to my mind - it was too late! The amputating knife would have divided the trunk of the artery below the axillary ligature! and the disease for which the operation had been undertaken would have been left behind. Moreover, at this date, a period of nearly three weeks from the first operation, not one wound had more than very partially healed. What was the prospect that a wound of some five inches in diameter, to which was superadded the additional drawback of exposed bone, would unite? The more I reflected on the question of amputation as a means of safety, the more I felt convinced it would have proved an element of increased danger, and I abandoned it. One alternative remained, and that I adopted-viz., to stop the bleeding at any expense to the arm, even though general gangrene were the consequence. I ordered the arm to be firmly rolled from the hand up to the neck with a force that would insure as near as might be the apposition of the opposite sides of the main arterial trunk of the entire extremity. This operation was most efficiently done. On the fourth day the bandage and compress were removed and re-adjusted, but withont hæmorrhage. At the suggestion of Sir Benjamin Brodie, I gave him for some days subsequently to the last attack of hrmorrhage twenty grains of alum three times a day. It, however, dis. turbed his stomach, and I ordered him citrate of iron and quinine, ten grains; compound tincture of cardamoms, two drachms, three times a day; he also took acetate of morphia, half a grain, every night. His health improved distinctly for the ensuing ten or twelve days, slight oozing of blood occurring at each wound whenever the arm was dressed. On the six. teenth, anxious throughout the case to avail myself of any sug. gestion founded in good sense and reason, I adopted the recommendation of my colleague, Dr. Burrows, and ordered him an ounce of lemon-juice three times a day.

During the early part of the month of April the wounds gradually enough" but firmly healed. The man's features bespoke a greatly improved condition of constitutional health, and at the present date, May 28th, he may be said to be convalescent. He is desirous of returning to his family and home, and assures me that he feels as capable of undertaking his daily occupations as he has ever been in his life.

This man owes his life to the incessant and most careful watching of Mr. Stanwell, my house-surgeon, and Messrs. Hodgson, Powne, and Campion, and though last, scarcely the least important link in the chain, the sister of Abernetliy's ward. No care, no vigilance short of that dictated by their unremitting devotion to the interests both of science and humanity, and which found my young medical colleagues day by day, and night after night, the bed-side attendant of their patient for a period of weeks, could have carried him through the crisis of this most anxious case. The men who would sacrifice their time, their labour, and their health (to one of whom the exertion proved serious) in such a case are amply rewarded by the triumph of their success.

I have two observations to make on the above case. I think that the antidote to that cachectic state of system, which ren. dered a wound of a large artery so dangerous in such a constitution, was found in the total change of diet from that his position in life compelled him to adopt. I will not assert that he did not derive advantage from the administration of gallic acid, of alum, and of lemon-juice; but without the beef and mutton, the wine and brandy, the steel and quinine, I am strongly persuaded we should have failed in subverting that condition of natural and inherent debility of system which was so eminently characteristic of the man.

When in the early part of his treatment it was suggested to me that amputation of the arm was my only alternative, I 
said not until I had tied every artery in his arm. My hope lay in improving the condition of his blood, and in this I think I may say I sueceeded. Without such success, amputation itself, however plausible, must have led to certain death.

Grosvenor-street, Jane, 1855.

\section{CASES OF NEURALGIA.}

WITH OBSERVATIONS.

By C. HANDFTELD JONES, M.D., F.R.S.

THe very great prevalence of aguish and neuralgic affections at the present time inclines me to think that short records of some of the cases which have fallen under my own observation may not be without interest.

CASE 1.-M. C-_, female, single, servant, aged twentyfive, much engaged in washing, of healthy, rather florid aspect, for a month has had pain of the right hand, affecting all the parts supplied by the median nerve. The pain is easier when the hand is used, is worse when she is still, and at night; no sleep; there is a feeling of numbness, as well as pain; tongue moist, clean; urine clear; bowels open. She never had gout or rheumatism; no members of her family have had gout, but a sister suffers in the same way as herself. A variety of remedies were at first tried, without benefit, such as iodide of potassium in smaller and larger doses; afterwards nervines, with carbonate of iron; then sulphate of quinine, two grains, with sulphate of iron, four grains, and electro-magnetism to the part. Some benefit was produced by seven minims of liquor arsenicalis, three times a day. There was less pain, but the fingers were very cold, numb, and powerless.

A month had now elapsed, when, on the 7 th of March, I began to give her quinine, in five-grain doses, three times a day.

March 10th.-Improved; sleeping better; had not near so much pain.

14th. - More pain in the hand, extending up to the elbow, the last two days. I increased the dose to ten grains.

17th. - Hand much better; much more free from pain.

24th. - Hand in no pain at all, only numb. I then gave her fifteen grains twice a day, desiring her to take it three times a. day, if she did not get well.

April 7th.- - Hand quite well for a week; has done her work; healich better. Discharged.

This case illustrates well the beneficial effect of large doses of quinine.

CASE 2.-H. O- a a admitted May 25th, 1854. She has symptoms of catarrh, but states, also, that for a long time her hands and fingers have felt numb and sleepy at times, and have been in violent pain at night. After the catarrh had been cured, I gave her quinine, two grains, with four grains of sulphate of iron, in a mixture, three times a day.

Ten days after this, she considered herself well enough to be diseharged, having still, however, slight numbing sensations, attended with some stiffness in the fingers of the right hand, affecting the ends mostly, as far up as the second joint.

In this case, small doses of quinine and iron were adequate to effect a nearly complete cure.

CASE 3.-C. B-, female, middle age ; not anæmic ; digestion weak; skin cool; pulse rather weak; bowels torpid; tongue clean; aspect healthy. Complains that when she gets into bed at night the fingers of both hands " go dead," those supplied by the ulnar nerve being first affected. The forearm seems to suffer in the same way. The numbness or pain does not come on till she has been asleep; it awakes her, and continues more or less all night. It is not felt during the day.

March 8th, - To have two grains and a half of disulphate of quinine; tincture of muriate of iron, fifteen minims; spirits of chloric ether, fifteen minims; water, one ounce, three times a day.

23rd.-Health better, and suffers less with her hands; is not awoke now at night, but has cold shivering feelings at this time. Quinine increased to four grains.

April 2nd.-Better in herself, and her appetite has improved. The attacks now come on towards morning, awake her about five or six, A.M., and last about half an hour. After the attack has passed off the hands and forearms feel painful not numb, the little and ring fingers being most affected. The attacks are much more prone to come on if she lies on either side. Skin quite warm. Looks the picture of health. Has chilly. gensations now and then. 9th. - Has the attacks still, but not so violent or so often; the pain remains in the hands and arms afterwards: they occur at the same time every morning. The region supplied by the ulnar nerve is now alone affected. She is easily fatigued by exertion.

16th. - The patient is very much better, almost well; has only slight remains of the neuralgia in the ulnar nerve region of the right hand; is not disturbed at night; has no cold shivering sensations. The weather changed from cold east to warm west wind. Not having seen the patient since, I conclude that she has recovered, as she was to call again if necessary. The quinine was clearly the principal agent in the cure, and it would no doubt have shortened the duration of the treatment had I given larger doses at the first. The periodicity of the attacks is worthy of remark, and the presence of shivering sensations, both of which circumstances indicate an affinity with ague. As the disorder declined, it confined itself more particularly to the ulnar nerve, which was the first to be affected in the paroxysms. This seems to me to indicate rather a peripheral than a centric affection.

CASE 4.-M. J-_ aged twenty-nine, female, married; tall, healthy-looking, but rather pale. Has been ill one month; suffers from pain in the hand and forearm, not extending above the elbow, severe at night, but only as a numb sensation in the day. All the fingers are affected. She is four months advanced in pregnancy. Is occasionally engaged in washing.

Jan. 23rd.-To take five grains of disulphate of quinine three times a day. No improvement having been produced at the end of a week, I doubled the dose. The next week she reported herself better; the fingers were affected, but not the forearm. The next time I saw her, as she was not improving, I gave her, for a week, liquor of chloride of arsenic, five minims three times a day, and after three days conjoined with it saccharized carbonate of iron, one scruple three times a day. This plan gave no promise of benefit.

On Feb. 20th, she was not better ; the pulse was very weak; she had no sleep after the pain came on at night. I then gave two grains of disulphate of quinine with four grains of sulphate of iron, in a mixture, three times a day; and a pill of one-third of grain of acetate of morphia and four grains of extract of henbane, at bed-time.

Feb. 27th. - She reported that her fingers were much better she had slept better and was stronger.

March 6th.- Has continued to improve; sleeps well; fingers feel numb; no pain at night; bowels open.

13th. -Is well; has no uneasy sensation in her fingers.

In this case, quinine and iron in combination were more effectual than large doses of quinine, or arsenic, or carbonate of iron. The expense of large doses of quinine is so considerable, that with hospital cases I generally try the combination of the sulphates mentioned above, or a similar one of the citrates, and in a good many cases it has answered very well. The sedative at night I believe to be decidedly useful in cases of this kind.

CASE 5.-E. E- - aged fifty-six, female, married; admitted on the 4th of September. She complains of pain in the right forearm, extending from the fingers up to the elbow, commencing in the mid-finger, of more burning character at night, not disturbing her rest, but very severe in the morning, when she cannot move her hand to open or close it. The fingers are often burning when she touches or holds anything; at other times numb. Foot somewhat similarly affected. Urine free, clear; pulse of good force; skin warm; is in tolerable health. Ordered, two grains of sulphate of quinine, four grains of sulphate of iron, and an ounce of water, three times a day. Five grains of colocynth pill with blue-pill, every other night

Sept. 14th. - Her fingers have lost the heat, but are numb; she cannot close them; attempting to use a needle makes them numb.

21st.-Less numbness, but feels pain up the arm into the axilla if she tries to lay hold of a needle.

28th. - Improving. To take three grains of quinine, three times a day.

Oct. 5th.-Not so well; all the fingers "go dead." To have four grains of quinine, three times a day.

12th. - Somewhat better; suffering from want of sufficient food. Continue quinine, and to take half an ounce of cod-liver oil three times a day.

19th.-Better diet; neuralgia not improved; is drowsy. To take ten grains of quinine, three times a day; continue oil. $26 \mathrm{th}$. - Not better. Ordered, a scruple of carbonate of iron, three times a day; an ounce of decoction of bark, a scrnple of muriate of ammonia, and three grains of carbonate of ammonia, three times a day. 